\title{
Marija Mitrović
}

Università degli studi, Trst, Italija

\section{Na zapadnoj margini - Balkan u Trstu}

Na krajnjoj zapadnoj granici Balkanskog poluostrva, u gradu Trstu, postojalo je više kulturnih, muzičkih, privrednih i sportskih organizacija koje su u svom nazivu sadržavale imenicu „Balkan“. „Palata Balkan”je zgrada u samom centru grada koja je izgorela 13. jula 1920. godine i smatra se prvom žrtvom fašizma u Evropi. Najveći deo zgrade zauzimao je hotel „,Balkan“, zatim Akademsko društvo „Balkan“" (formirano 1907, zabranjeno 1927, ali je kao tajno postojalo sve do1938, a izmešteno u Soveniju čak i do 1957). Tokom Devedesetih godina u Trstu je postojao „Radio Balkan“, a na početku novog milenijuma periodična publikacija "Balkan, rivista illuminista" (prosvetiteljski časopis). Na političkom planu tokom novog milenijuma u Trstu se poklanja velika pažnja tzv. Zapadnom Balkanu; u sedištu Regije Friuli Venezia Đulia održano je više sastanaka o procesu integracije postjugoslovenskih zemalja u Evropsku Uniju. - U radu se opisaje profil i delatnosti ustanova koje u svom nazivu nose naziv „Balkan“, ali se traga i za odgovorom na pitanje: koji sadržaji, kakva priroda ovog u suštini geografskog, ali u većini slučajeva $i$ vrednosnog pojma se može iščitati iz ove tršćanske ,balkanofilije“.

Ključne reči: Trst, Balkan, privredne delatnosti, asocijacije, radio, periodične publikacije; Zapadni Balkan

U gradu koji se nalazi na krajnoj zapadnoj granici Balkana niz kulturnih, muzičkih, sportskih, privrednih asocijacija i institucija sadrži ili je sadržavalo odrednicu „Balkan“ u svom nazivu. Ona se istina pojavljuje i u nazivima članaka, studija, romana, periodike u čitavoj Italiji, ali se grad Trst posebno ističe frekventošću upotrebe ove oznake.

Ne mogu reći da imam sasvim precizan odgovor na pitanje šta motiviše ovu učestalost, mislim da je to tema koja iziskuje znatno šire i dublje istraživanje. Ja ću se u ovom radu zadržati na nekolikim zapažanjima, verujući da ona mogu podstaći i dalja istraživanja, na istorijskom, antroploškom, sociološkom i kulturološkom nivou. 
Imenica Balkan ulazi u ovu geografsku zonu na velika vrata početkom 20. veka: godine 1904. u samom centru grada nikla je velelepna zgrada, sagrađena prema nacrtu poznatog bečkog arhitekte, Maxa Fabianija, slovenačko-italijanskog porekla. U nju je smešteno niz poslovnih, kulturnih, sportskih ustanova i društava, a najviše prostora je zapremao hotel „Balkan“. Vlasnici ove zgrade označavali su je kao Narodni dom. Međutim, u gradu je cela zgrada, a ne samo hotel, i do danas poznata kao „palazzo Balcan - palata Balkan“.

Zamisao o izgradnji jednog ovakvog polifunkcionalnog centra nastala je godine 1901. u slovenačkom političkom društvu „Edinost“ (Jedinstvo), koje je bilo aktivno još od 1876, te izdavalo svoju publikaciju, dnevnu novinu „Edinost“. ${ }^{1}$ Prema popisu stanovništva iz 1910. godine u Trstu je živelo 56.926 Slovenaca, što je činilo 29,82 posto ukupnog stanovništva toga grada. Ako se uzme u obzir i šira okolina Trsta, taj se broj penje na $70.632 .{ }^{2}$ Kao starosedeoci, Slovenci, koji su se u početku pretežno bavili zemljoradnjom, živeli su na periferiji grada. U vreme maksimalnog ekonomskog procvata Trsta u drugoj polovini XIX veka, i među Slovencima raste broj trgovaca, zanatlija, bogatih i obrazovanih ljudi, čiji je život i rad vezan za centar grada. Luka - najveća u tadašnjem Habzburškom carstvu - privukla je u određenim istorijskim okolnostima kako Italijane iz Venecije, pa čak i Đenove, tako i Grke, Jevreje, Srbe, Hrvate... Kako je Trst bio treći grad po veličini u tom carstvu, jasno je da je tu živeo i veći broj nemačko govorećih stanovnika (prema istom popisu, nemački jezik je bio maternji za 11.856 stanovnika ovoga grada). Etnički, jezički, religiozno i kulturološki različiti narodi su se potrudili da u samom centru grada sagrade sopstvenu markantnu crkvu (učinili su to Srbi, Grci, Jevreji, protestanti i anglikanci). Godine 1901. i Slovenci odlučuju da svoje prisustvo istaknu monumentalnom građevinom u centru grada, ali čija namena neće biti sakralne, nego svetovne prirode. Podigli su svoj Narodni dom u ulici Fabio Filzi 14 (danas sedište Fakulteta za prevodioce i tumače) na terenu koji su u tu svrhu kupili. Od samog početka investitori su postavili zahtev da se impozantna zgrada mora izdržavati sama, sopstvenim delatnostima. Bilo je u Narodnom domu mesta za kulturu (čitaonica, pozorište, umetnička i kulturna

${ }^{1}$ U vreme fašizma, 1928, bila je zabranjena kako organizacija, tako i dnevna novina. - Zanimljivo je da je 90 godina kasnije, godine 2018, jedan mladi umetnik iz Venecije, Alessio Mazzaro, uz finansijsku potporu male izdavačke kuće „Asterios“ iz Trsta i čuvenog istorijskog kafea San Marko, pokrenuo periodičnu publikaciju istog imena, formata i grafičkog izgleda, u kojoj prostor dobijaju glasovi pripadnika različitih nacija, koje žive u Trstu. Broj 5. iz februara 2018. posvećen je srpskoj kulturi i prisustvu Srba u Trstu. Autori priloga ovog broja su: Bojan Mitrović, Ravel Kodrič, Pierluigi Sabati, Charles Simić i Jelena Todorović.

${ }^{2}$ Podatke navodimo prema knjizi: Milan Pahor, Slavjanska sloga. Slovenci in Hrvati v Trstu. Trst 2004, str.124-125. 
udruženja, gimnastička sala, sportska udruženja, češko, a uskoro i rusko kulturno društvo), ali je akcenat stavljen na produktivne delatnosti: kafeterija, restoran, banka, štamparija, i - kako je već rečeno - najveći prostor zapremao je hotel „Balkan“. Prema tvrdnji arhitekte prof. Marca Pozzetta ${ }^{3}$, bio je to jedan od najluksuznijih hotela toga vremena. Raspolagao je čak sa 62 sobe, sve su bile sa kupatilom, što tada nije bilo uobičajeno. Uskoro, grad je - kao što smo napomenuli - celu zgradu imenovao tim imenom: Balkan. U toj je zgradi osnovano i imalo sedište i akademsko društvo Balkan - o kojem ćemo malo kasnije reći nešto više. U dogovoru sa Prvom hrvatskom štedionicom iz Zagreba, Jadranska banka sa sedištemu u Narodnom domu formirala je 1910. godine društvo „Balkan“ u Ljubljani, a naredne godine je u Trstu oformila Trgovačko, špedicijsko i komisiono dioničko društvo „Balkan“. U upravni odbor ovog finansijski moćnog preduzeća izabrani su viđeniji trgovci kako iz Trsta (među njima u srpski trgovac Špiro Kvekić), tako i ugledni ljudi i profesori iz Praga, Zagreba, Sarajeva.

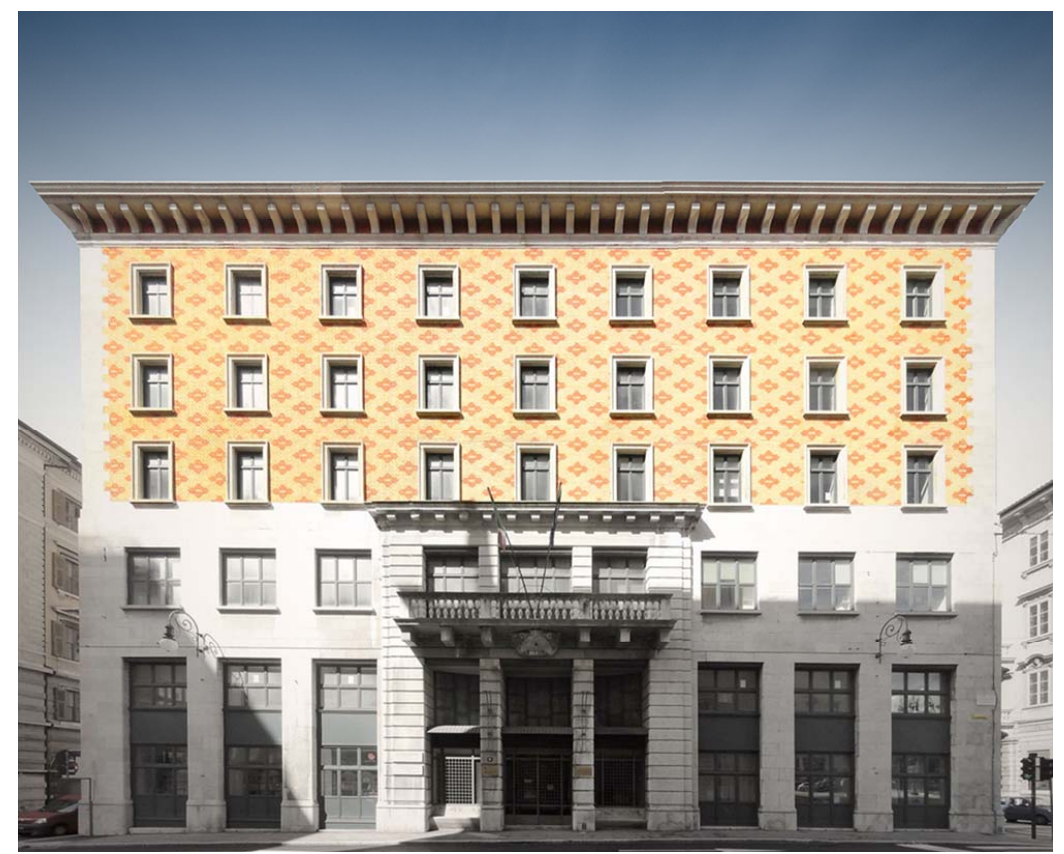

Fasada zgrade „Balkan“, odnosno Narodnog doma, danas sedište Fakulteta za tumače i prevodioce

${ }^{3}$ Marco Pozzetto, „Uvod v nezgode Fabianijeve mojstrovine“. In: Erik Dolhar, Marko Korosic, Narodni dom - Balkan. Ob 80-letnici požiga. Založba Branko \&Založba Jutro, Trst, Nova Gorica - Ljubljana, 2000, str. 11-12 
Kako ističe tršćanski profesor Jože Pirjevec, odlični poznavalac istorije slovenskih zemalja, ,svojom naglašeno laičkom namenom i poslovnom delatnošću, Narodni dom je bio nešto sasvim novo i različito. Nametao je pitanje uloge vladajuće elite u gradu, pošto je radom pozorišta, hotela, restorana, banke i prostora namenjenih društvenim i političkim ciljevima, prkosio nacionalno-liberalnom Trstu i njegovim simbolički značajnim ustanovama. Obznanio je da je Trst ekonomsko i kulturno središte širokog, ne samo slovenačkog, nego sveslovenskog zaleđa, čime je otvorio temu trijalističkog preuređenja Habzburške monarhije.“ (Pirjevec, 2000 : 15)

Sasvim u skladu sa idejom o objedinjavanju, povezivanju što većeg broja slovenskih naroda - na čemu je insistirao politički pokret Edinost, a kao što smo videli - baš na njegovu inicijativu je izgrađen Narodni dom - i sam pojam Balkan je u Trstu na početku XX veka pokrivao samo slovenski deo Balkanskog poluostrva. To se veoma lepo ogleda i u delovanju akademskog društva „Balkan“, koje su 1907. osnovali slovenački, zajedno sa hrvatskim visokoškolcima Trsta, a sa sedištem u samom Narodnom domu. Povodom 50 godina od osnivanja ovog društva, godine 1957, objavljena je zanimljiva knjižica. ${ }^{4}$

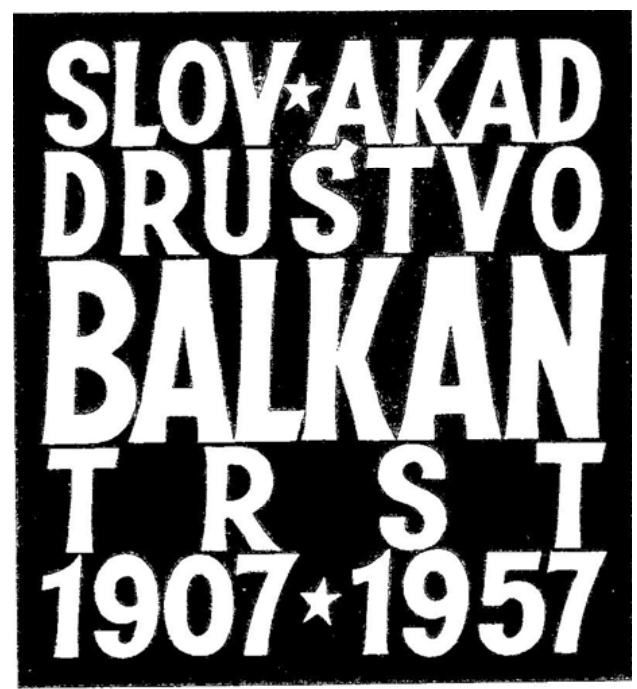

Naslovna strana publikacije u kojoj je opisan rad Akademskog društva Balkan

${ }^{4} 50$ let slovenskega akademskega društva Balkan v Trstu. Bez imena autora ili urednika publikacije, a sa prilozima nekada aktivnih članova toga društva: dr Karel Ferluga i Dr F. Mikuletić pišu „Kratka zgodovina Akademskega društva „Balkan“ (3-13); Mikula Letić, „Rideamus Balcaniter“ (14-27), Robert Hlavaty, „Moj najlepši spomin na Balkan“ (28-29); Dr Jože Berce, „Zakaj mi je žal po 'Balkanu'“ (30-31), i na kraju: Fran Rapotec, Gorski vijenac (31-32) 
Iz ove knjižice saznajemo da su društvo „Balkan“ činili akademci na studijama tada najčešće u Pragu, ređe u Gracu (Trst dobija univerzitet tek 1924. godine), ali i na Višoj ekonomskoj školi u Trstu; izričito se kaže da su svi Slovenci i Hrvati upisani u tu višu školu bili članovi Akademskog društva Balkan.

Od samog početka ova akdemska asocijacija bila je veoma aktivna: sastanci su se održavali jednom nedeljno, s tim što je prvi deo sastanka bio posvećen nekom predavanju (teme su bile veoma raznolike, učesnici, po sećanju navode da su obrađivane teme kakve su na primer: Ekonomski odnosi između Srbije i Bosne i Hercegovine; ili - Značaj narodnih biblioteka, ili - Produkcija piva), predavači su bili sami članovi društva, ali i viđeniji ljudi iz grada. Posle službenog, usledio bi društveni deo, plesovi, šale, pesma, muzika... Članovi su polagali veliku pažnju prikupljanju i kupovni knjiga za sopstvenu biblioteku; te su knjige onda kružile među članovima. U periodu do početka Prvog svetskog rata, dakle za manje od sedam godina, članovi društva su ustanovili čak 12 javnih biblioteka u 12 sela u okolini Trsta, sa ukupno oko 3000 primeraka knjiga. Novac za kupovinu knjiga pribavljali su organizujući veoma uspešne zabavne i muzičke večeri. Sami su bili i bibliotekari u tim svojim ,isturenim odeljenjima“, vodili evidenciju o izdavanju i vraćanju knjiga... Takođe, kada bi koji student zapao u finansijsku krizu, kada nije mogao da plati univerzitetske takse ili put do Praga ili Graca, na isti način su se - uvek veoma uspešno - prikupljala sredstva i za ove namene.

Akademsko društvo „Balkan“ bilo je dakle izuzetno aktivno kako na socijalnom tako i na kulturno-edukativnom planu. Iako njegovo delovanje nije bilo dugog veka, veza između pojma Balkan i želje za edukacijom neće se iscrpsti i nestati u trenutku kada je delovanje ovog tršćanskog akademskog društva zabranjno. Pojam Balkan je u Trstu povezan i sa prosvetiteljskim akcijama.

Prva velika istorijska teškoća s kojom se akademsko društvo „Balkan“ suočilo bio je Prvi svetski rat. No, ni kraj rata i prelazak Trsta iz Habzburške monarhje u kraljevinu Italiju nije doneo ništa dobro: već 13 jula 1920. godine Narodni dom je zapaljen od strane fašističkih radikala, te se delatnost potom odvijala po obližnjim selima. Kompletna dokumentacija o radu ovog društva, kao i sve drugo što je postojalo u Narodnom domu izgorelo je. Godine 1927. fašistički režim zabranio je rad društva, kao i sve vrste kulturnih akcija i događanja koja se nisu odvijala na italijanskom jeziku; no pojedini članovi su i nadalje, najmanje do 1938. organizovali razne tajne sastanke i skupne izlete u Sloveniju i Istru. 


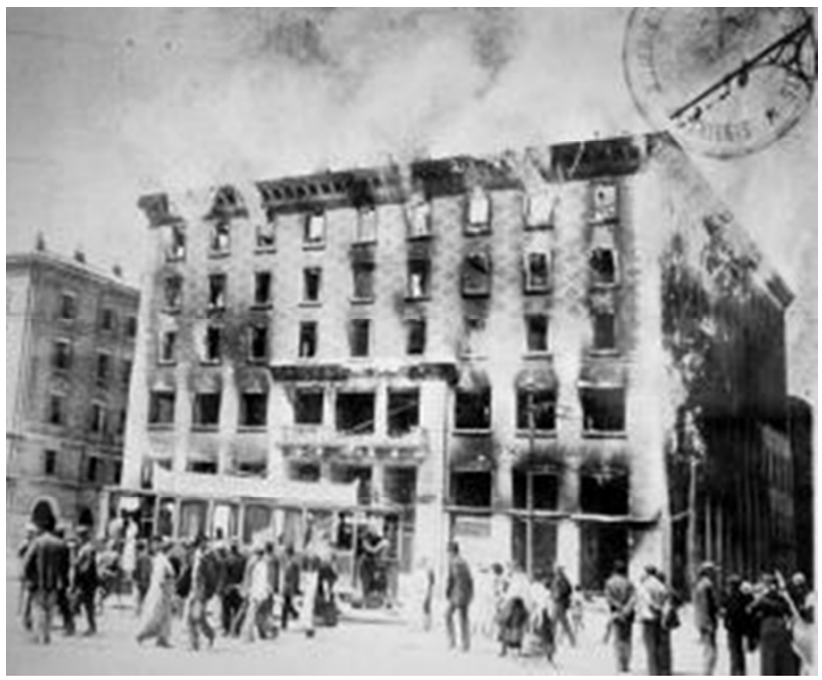

13. jula 1920. zapaljen je Narodni dom poznat pod imenom ,palata Balkan“"

Pošto im je izgorela čitava dokumentacja, knjižica koju su nekadašnji „Balkanci“ objavili 50 godina nakon osnivanja Društva donosi istorijat ove asocijacije isključivo od materijala prikupljenog iz lista Edinost; lokalni dnevni list je, dakle, pratio rad Društva. Za ovu priliku bih pažnju zadržala samo na jednom prilogu koji je nekadašnji član društva „Balkan“ a potom „diretur, sviju zetskih pošta providur", Fran Rapotec, sastavio u čast tridesetogodišnjice postojanja društva, te ga naslovio sa - Gorski vijenac! Ovako poje „Galamdžija Franjo“" taj svoj „spev“:

Viđi vraga su sedam binjišah:

na mom stolu poziv njegov smjeli!

Poziv Biksa čuvenog imena

s tršćanskijeh kršnijeh obala, najsjevernijeg njegda Balkana!

Viđi vraga! - Krstim se i čudim:

Da li još mu žilca ne uginu njegovome đavolijem sinu, onom kriještavom sivom tiću, sivom tiću Mikula Letiću! ${ }^{5}$

${ }^{5}$ Mikula Letić je bio urednik humorističkog lista Biks, što su ga „balkanci“ pokrenuli 1909; nije sačuvan nijedan broj 
Iste godine kada je formirano akademsko društvo „Balkan“, pod istim je imenom u Trstu pokrenut jedini hrvatski tršćanski dnevni list, koji je izlazio od 1. septembra 1907, ali je iz materijalnih razloga prestao s izlaženjem već 30. aprila 1908. U ovom listu postojala je stalna rubrika Slavenski jug, a u nastavcima je tu objavljena čuvena Nazorova priča Veli Jože.

Godina 1920. kada je zapaljen Narodni dom prekretnica je u životu tršćanskih Slovena. Nije izgoreo samo značajan kulturni i proizvodni centar tršćanskih Slovenaca; tim gestom najavljeno je ono što će doneti fašizam: zatvaranje u jednu kulturu, ukidaje svakog dijaloga sa drugim i drukčijim kulturama. Nije nimalo čudno što je baš u tom gradu 18. septembra 1938. godine Mussolini proglasio rasne zakone. Slavofobija je tu već bila na delu, i oko 200.000 prisutnih na glavnom gradskom trgu, Piazza Unità, s oduševljenjem je prihvatilo i proglašavanje zakona kojim se Jevrejima ukida svako pravo. Od preko 5000 Jevreja koliko je do tada živelo u Trstu, njihov je broj posle II svetskog rata sveden na jedva nešto više od pet stotina (danas ih ima nešto više, oko 700, ali je njihov kulturni život u gradu i te kako aktivan: osim osnovne škole, zabavišta, letnje škole, imaju i Muzej, sinagogu drugu po veličini u Italiji, organizuju neobično mnogo susreta, konferencija, kurseve jezika...).

Ni kada je fašizam pao (1943) i cela Italija doživela oslobođenje (25 aprila 1945), grad Trst nije doživeo preporod. Sve do 1954. godine on je živeo kao „slobodna teritorija“, ali pod upravom Zapadnih sila (Britanija i SAD pre svega). Do procvata nije došlo ni posle ponovnog integrisanja Trsta u republiku Italiju koja dugo nije razumela, nije shvatala pravi karakter vekovno etnički raznovrsne strukture ovoga grada. I tek 90 tih godine grad se ponovo otvara, oživljava prezentacija i dijalog sa drugim kulturama, tradicionalno prisutnim u gradu, ali do tada marginalizovanim.

Godine 1999. u jednom tekstu objavljenom u visokotiražnom nacionalnom dnevnom listu La Reppubblica, trščanski novinar i pisac, Paolo Rumic (Rumiz), beleži: „kao da implozija Jugoslavije nije prestrašila Trst, nego je smanjila napetost $\mathrm{u}$ odnosu prema slovenskom svetu. Grad koji je sebe doživljavao kao isključivo italijanski (italianissimo) ludi za muzikom Gorana Bregovića i filmovima Emira Kusturice. Vatrene makedonske muzičke grupe koje u goste poziva Opština Trst, sviraju na glavnom trgu (piazza Unità), 'svetom' mestu lokalpatriotizma, a niko ni da se osvrne na taj paradoks. I tako, umesto grada duge memorije, pred nama je arhipelag šutnje“ ${ }^{6}{ }^{6}$ istom članku Rumic citira psihoanalitičara Paola Fondu, koji ističe: „U času kada NATO bombar-

${ }^{6}$ La Reppubblica, 10/05/1999. Tekst nosi naslov: „Il silenzio glaciale di Trieste eterna frontiera di guerra“. Citat glasi u originalu: „è come se l”mplosione della Jugoslavia, anziché impaurire Trieste, ne avesse sdrammatizzato il rapporto col mondo slavo. La città italianissima impazzisce per le musiche di Bregovic e i film di Kusturica. Scatenate bande macedoni, invitate dal Comune, hanno portato i Balcani nel luogo 
duje Srbiju, Trst je naizgled indiferentan prema tom činu, ali u biti grad je postao tolerantniji“. Već tokom prvih godina ratova iz Devedesetih smanjile su se ideološke podele, a kada je srušen režim i kada se federacija raspala, grad je nekako osetio da tamo, preko granice više nema ,slavo-komunističkih hordi“". I još nešto: baš tokom tih ratova, Tršćani su naučili da razlikuju narode. Mnoge familije iz te "ex“ zemlje nastanile su se u Trstu i dale gradu neophodnu linfu, koja mu je nedostajala. I tako danas, Slovenci, Hrvati, Srbi, Bosanci polako postaju ono što su različiti narodi bili u vreme Austro-ugarske: konstitutivni deo grada. Njihovim prisustvom počeli su da se ruše i stereotipi koji su u gradu vladali, a odnosili se na „mondo slavo“.

$\mathrm{S}$ jedne strane u gradu i čitavoj pograničnoj regiji FVG javlja se, dakle, masovno interesovanje za kulturu (muziku i filmove pre svega) slovenskog dela Balkana, a s druge valja zabeležiti i sasvim individualne poduhvate, nešto što bismo mogli označiti kao „one man show“. Mislimo ovde pre svega na jednu radio stanicu, koja se zvala „Radio Balkan“ i išla u etar od 1995. do 1999. Pokrenuo ju je i vodio Fabio Mosca, tada već penzionisani tehničar RAI. Sam je napravio jednu malu radio stanicu, posedovao je svoje radio frekvencije, koje je najpre godinama ,iznajmljivao" grupi anarhista (radio se njihov zvao Radio Libertario), a onda, kada su tokom ratnog vihora iz Devedesetih u Trst prispeli brojni ljudi sa Balkana i kada se o krizi raspada Jugoslavije i u ovom gradu često diskutovalo, Fabio Mosca je postavio zahtev da se radio stanica okrene baš ovoj problematici. Kako anarhisti na to nisu pristali, Mosca prilazi grupi još radikalnije levo orijentisanih, tzv. Autonomista, te 1995. pokreće „Radio Balkan“.

U sećanju jednog od aktivnih pripadnika ove grupe, označene kao Autonomi, ${ }^{7}$ ova mala radio stanica, „Radio Balkan“, veoma omeđenog dometa je svako jutro od 7,30 do 8,30 emitovala pregled štampe, lokalne, nacionalne i evropske; prenosili su i komentarisali sve ono što se tada o Balkanu pisalo.

più 'sacro' del patriottismo locale, piazza Unità, e nessuno s' è voltato indietro. Così, la città dalla lunga memoria pare un arcipelago di silenzi.“

${ }^{7}$ Zahvaljujem se Andrei Olivieriu, jednom od tada aktivnih članova grupe Autonomi, koji mi je u razgovoru obavljenom 8 oktobra 2018. na osnovu svojih sećanja oživeo rad ove radio stanice, kao i čitave grupe koja je sebe prepoznavala pod sloganom: „Razzismo stop“. Prema iskazu ovog aktivnog saradnika pokreta i radio-stanice, do gašenja Radio Balkana došlo je usled rascepa između grupe „Autonomi“ i vlasnika radio-stanice, Fabia Mosche. Mosca je naime smatrao da je NATO bombardovanje Srbije u martu 1999. nužno zlo koje ima za cilj skidanje sa vlasti Miloševićevog režima, Autonomi, međutim, ostaju dosledno antiratno orijentisani, ističu da se oružjem ne rešava problem, da su žrtve bombardovanja pre svega civili; čak jedna njihova delegacija odlazi u Beograd pod bombama da tamo iznese svoje antiratne i antinacionalističke stavove. Fabio Mosca zatvara svoju radio stanicu, prodaje frekvencije i zauvek napušta svoj hobi osnivanja i vođenja radio-stanice. 
Sredinom Devedesetih ova grupa mladih je organizovala letnji festival muzike sa Balkana, i to ne samo folk, nego i rock muzke. Istih tih godina, za vreme održavanja filmskog festivala „Alpe Adria“ (uvek tokom januara meseca), festivala na koji su - uprkos sankcijama pod kojima je bila Srbija - dovođeni i filmovi iz te republike, članovi ove grupe organizovali su poseban štand sa oznakom „Radio Balkan“. Brojni prikazi festivalskih filmova išli su u etar preko frekvencija „Radio Balkana“.

I tu nije kraj: već sledeće 1996. godine Fabio Mosca želi da pokrene i periodičnu publikaciju „Balkan - rivista illuminista“ (Balkan - prosvetiteljski časopis - i eto gde se vraća ona jaka želja za prosvećivanjem, koju smo sreli i u akademskom društvu „Balkan“ sa početka 20. veka). Časopis dobija sve dozvole i počinje da izlazi tek 2001, pa iako u katalogu najstarije javne biblioteke u gradu Trstu, koja nosi naziv Biblioteca civica (osnovana je 1793), piše da on izlazi do 2008, u biti on postoji samo do 2005. Objavljeno je ukupno 9 brojeva, poslednji je izišao decembra 2005.

U biblioteci sam poručila svih devet „tomova“ (volumi, piše u katalogu) i ne malo se iznenadila kada sam celi materijal dobila u jednoj maloj, polupraznoj kutiji (format publikacije je naime $10 \mathrm{x} 14 \mathrm{~cm}$ ), a na naslovnoj strani svih tih svezaka (od kojih svaka ima samo 32 strane, a poslednji broj samo upola, dakle 16) uvek stoji: „Trieste medievale fuori dai miti“ (Srednjevekovni Trst bez mitova) $)^{8}$. Jedini autor svih 9 brojeva je Fabio Mosca. Ovaj je autor naime odlučio da istoriju Trsta od rimskog perioda do sredine 15 veka (1439), prikaže kritički. Kao i većina istorija gradova - a tu je Beograd doista među vodećima po stepenu mitizacije svoje prošlosti - $\mathrm{i}$ tršćanska srednjevekovna istorija često se prikazuje uz pomoć legendi, a ne dokumenata. Cilj ove publikacije je da u nastavcima i na pristupačan način ispriča kritičku, na dokumentima zasnovanu prošlost grada Trsta. - Ali: zašto i kako onda ovaj naslov: Balkan - rivista illuminista? Odgovor na ovo pitanje nemam!

Neki plodovi emisija emitovanih na „Radio Balkanu“ sačuvani su u obliku publikacija. Svakako najvažnija, najoozbiljnija jeste „,Dossier “ Radio Balkana, koji je 2000. godine objavljen kao posebna knjiga pod naslovom I Serbi, nel medioevo balcanico (dal VI secolo ad oggi). Autor je Kazimiro (Casimiro) Muha. Knjiga je većeg formata /A3/ i broji 96 strana sitnog sloga. Ima deset poglavlja sa ukpuno preko 100 potpoglavlja i obuhvata istoriju Srba od vremena kada su imali zajedničku državu sa Bugarima, pa sve do Devedesetih godina 20. veka. Knjiga je ozbiljno pripremana, na kraju autor navodi vrlo bogatu i raznovrsnu literaturu. Prikazujući teške, Devedesete godine, autor

${ }^{8}$ Odgovorni urednik je Marco Crimi. A sudska dozvola za objavljivanje publikacije odobrena je u sudu pod oznakom: Aut. Trib. di Trieste n. 940, c.p. 1843 već 1996. Bez imena izdavača. 
donosi odlomke iz knjige Druga Srbija, koju je za italijansku publiku priredila Melita Richter Malabotta (Selene edizioni, Milano 1996), a koja je nastala na osnovu dva zbornika što ih je pod naslovom Druga Srbija objavio Beogradski krug (1992. i 1993). Autor nastoji da pokaže razvojnu liniju nacionalizma, koja je posebno ojačala Osamdesetih godina, ali beleži i one glasove koji su se glasno suprotstavljali ne samo nacionalizmu, nego i svakom ratnom rešavanju sukoba.

U novom milenijumu prisutna je u gradu i celoj regiji Friuli Venezia Giulia jaka želja da se Regija kao institucija aktivno uključi u posredovanje u približavanju zemalja Zapadnog Balkana normativama, pogledima, stavovima izgrađenim u EU. Tu sada dakle više nije reč o Balkanu, nego o Zapadnom Balkanu, koja je čisto politička kategorija i označava balkanske zemlje koje još nisu ušle u EU.

Godine 2014. u Berlinu je organizovana važna diplomatska inicijativa pod pokroviteljstvom Angele Merkel, kojoj je potom usledila Bečka (2015), pa Pariska (2016) i Tršćanska (2017) konferencija na nivou predsednika vlade svih zemalja tzv. Zapadnog Balkana, zajedno sa predsednicima zemalja EU, a u cilju ozbiljnih priprema balkanskih zemalja za njihov ulazak u EU: Ali već 10 godina pre berlinske inicijative, u Trstu je u sedištu Regije FVG održan skup pod naslovom: I Balcani occidentali verso l'integrazione nell'Unione Europea - Prospettive e ruolo del FVG. Trieste 29. novembra 2004. Izdat je potom i u jednu fasciklu uvezan sav materijal pod upravo ovim naslovom, a sa izlaganjima iznetim na tom sastanku u Regiji.Tu se ističe pre svega neko „istorijsko pravo“" Regije da sudeluje u ovom procesu. ${ }^{9}$

Kao i većina debata koje se odvijaju na političkom planu, i ova je ostala lepo formulisana, ali se ostvarilo malo: rečeno je kako se programi integracije novih država moraju odvijati u skladu sa potrebama samih tih zemalja, ali nije osnovano nikakvo telo, holding grupa ili slično, koja bi objedinjavala sve te prezentirane ideje i sve želje za poboljšanjem komunikacije između ove regije

${ }^{9}$ Navode se argumenti, pa se ističe da je u Trstu sedište Centralno-evropske inicijatve (INCE), a ova je rođena na osnovu ranijeg povezivanja zemalja srednje Evrope pod oznakom Regija Alpe-Adria - činile su je zemlje između Dunava i Jadranskog mora; prve inicijative za ovo povezivanje nastaju već 1978, a Regija Alpe-Adrija ostvaruje se 1988. Sedište joj je bilo u Trstu. Tu je ubrzo osnovan i filmski festival pod imenom Alpe-Adria Festival, a danas je to Trieste film festival: no uvek, čak i u vreme sankcija pod kojima je živela Srbija, na ovom festivalu važnu ulogu su imali filmovi sa celog Balkana. - Godine 1968. u Trstu je osnovan Istituto di studi e documentazione sull'Europa orientale, koji je 1987 preimenovan u Istituto di studi e documentazione sull'Europa comunitaria e l'Europa orientale; januara 2008 se Institut seli u Goricu i postaje Informest. 
i balkanskih zemalja. No, sastanci sa ovom tematikom se i nadalje, barem jednom godišnje, održavaju u sedištu Regije FVG.

Na zapadnoj margini geografskog prostora koji se označava kao Balkansko poluostrvo, pojam Balkana počeo se češće pojavljivati kao naziv za oređene institucije i udruženja na prelomu vekova, i to ne samo na prelasku iz 19. u 20. vek, nego i na kraju 20. i tokom prve decenije 21. veka. Zašto je to tako, koji su uzroci ove, u izvesnom smislu vremenski simetrične pojave? Za sada - jedini odgovor je: u oba slučaja, decenije tokom kojih je imenica Balkan u Trstu postala učestala, taj je grad doživeo otvaranje prema kuturi drugog i drugačijeg. Tradicionalna slavofobija pretvorena je u slavofiliju. A sama imenica Balkan izgubila negativne konotacije koje joj se atribuiraju ne samo na Balkanskom poluostrvu, nego i inače u svetu.

Koga zanima prisustvo balkanske muzike u svetu, stoji mu na raspolaganju ova elektronska adresa:

http://balkanarama.com/bands.htm. Italija tu nije među zemljama koje se mogu pohvaliti mnogobrojnim bendovima, čiji se repertoar zasniva ili barem polazi od balkanskih ritmova i tradicionalne balkanske muzike: navedena su 4 orkestra u kojim dominira ova tradicija, a od ta 4, dva su u Trstu: Kraški ovčarji i Balkan babau. Ono što će verujem svakog iznenaditi jeste broj bendova ove vrste u SAD: ima ih barem na spomenutoj adresi čak 95!

Nisam nikakav stručnjak za ovu vrstu muzike. Ipak izdvajam grupu Kraški ovčarji, koja postoji od 1994, nastupala je na brojnim koncertima širom Italije, ali i u svetu (mesec dana turneje po Južnoj Americi, na primer). Povodom deset godina svog postojanja izdali su sveščicu, u kojoj su se predstavili: svi su redom muzički veoma obrazovani.

\section{Literatura}

Anonim, 50 let slovenskega akademskega društva Balkan v Trstu. Graphis, Trst 1957. 32 str.

Balkan - rivista illuminista, brojevi 1-9. (Izdavač nije naznačen), Trieste 2001-2005 Bortuzzo M. ed altri, I Balcani occidentali verso l'integrazione nell'Unione europea : prospettive e ruolo del Friuli Venezia Giulia: Sala Illiria, Stazione marittima, Trieste 29 novembre. 2004. - Umnoženi materijal (ukupno 5 referata čuva se u Biblioteci Regije FVG).

Edinost, br. 5, februar 2018. Capitolo serbo.

Muha Casimiro (izabrao i uredio) I Serbi nel medioevo balcanico. Dossier di Radio Balkan. Trst 2000.

Pahor Milan, Slavjanska sloga. Slovenci in Hrvati v Trstu. Trst 2004, str.124-125.

Pirjevec Jože, „Pogled zgodovinarja“. In: Narodni dom - Balkan: ob 80-letnici požiga. (ur. Dolhar E., Korosic M.) Založba Branko \& Založba Jutro, Trst, Nova Gorica - Ljubljana, 2000. str. 15. 
Pozzetto Marco, „Uvod v nezgode Fabianijeve mojstrovine“. In:, Narodni dom - Balkan. Ob 80-letnici požiga. (ur. Dolhar Erik, Korosic M.) Založba Branko \&Založba Jutro, Trst, Nova Gorica - Ljubljana, 2000, str. 11-12.

Rumiz Paolo, „Il silenzio glaciale di Trieste eterna frontiera di guerra“ In: La Reppubblica, 10/05/1999. Čitano marta 2019 na sajtu: https://ricerca.repubblica.it/ repubblica/archivio/repubblica/1999/05/10/il-silenzio-glaciale-di-trieste-eterna-frontiera.html

\section{Marija Mitrović}

\section{At the Western Frontier - the Balkans in Trieste}

\section{Summary}

On the westernmost limits of the peninsula, quite a few cultural, musical, sports and economic associations have sprung, with the word "Balkan" in their name. In Trieste the word "Balkan" comes up with staggering frequency. "Hotel Balkan" was the informal name of the Slovene cultural center, a building in the very center of the city, burnt down on July 13th 1920 as one of the first "victims" of fascism in Europe. In that same building, aside from the hotel named "Balkan", there was an association of young academics with the same name (formed in 1907, banned in 1927, but continued to exist at least until 1938, and maybe even 1957). During the 1990's Trieste had a radio station "Radio Balkan" and in the beginning of the new millennium, a periodical "Balkan, rivista illuminista" (Enlightenment review). The new millennia also poses the accent on Western Balkans - as the former Yugoslav countries near the EU integration.

This paper focus on describing the activities that hold "Balkan" in their title, but also try to answer the question: what kind of value-judgement can be inferred beneath this triestine "balkanophilia".

Key words: Trieste, Balkan, activities, associations, radio, journal; Western Balkans. 